\title{
Genetic Analysis and Diversity Study among High Zinc Wheat (Triticum aestivum L.) Germplasm
}

\author{
Stuti Krishna ${ }^{1}$, Priyanka Upadhayay ${ }^{1}$, Vinod Kumar Mishra ${ }^{1}$, Shubhra N Kujur ${ }^{1 *}$, \\ Monu Kumar ${ }^{1,2}$ and Punam S. Yadav ${ }^{1}$ \\ ${ }^{l}$ Department of Genetics and Plant Breeding, Institute of Agricultural Sciences, BHU, \\ Varanasi, U.P., India \\ ${ }^{2}$ ICAR-Central Research Institute for Jute \&Allied Fibres, Barrackpore, W.B., India \\ *Corresponding author
}

Keywords

ANOVA, Diversity analysis, $\mathrm{D}^{2}$

statistics, GCV,

PCV

Article Info

Accepted:

05 February 2020

Available Online:

10 March 2020

\section{A B S T R A C T}

Wheat is the most important cereal grain crop in the world and is an important dietary nutritional source. High genetic variability is the prerequisite for the genetic improvement of traits. Yield and yield components can be increased by studying the diversity between genotypes and successfully utilizing them in selection and hybridization program. Fifteen wheat germplasm were taken in this study and evaluated for genetic diversity analysis. Genetic estimates like GCV, PCV, heritability and genetic advance were calculated. Analysis of Variance (ANOVA) and $\mathrm{D}^{2}$ statistics were conducted for different genotypes and traits understudy. Significant differences were observed for different traits under ANOVA. Fifteen genotypes were divided into six clusters based on $\mathrm{D}^{2}$ statistics. These studies show that crosses between the Cluster V \& VI and cluster III \& VI will give maximum number of segregants and thus is good for varietal improvement.

\section{Introduction}

Wheat is one of the most important cereal food crop grown worldwide. Wheat (Triticum spp.) is considered as one of the Neolithic founder crops which is known to be domesticated alongside other cereals viz., Einkorn wheat (Triticum monococcum L.) and barley (Hordeum vulgare L.) as well as pulses in the Near-Eastern Fertile Crescent approximately 10,000 years ago (Lev-Yadun et al., 2000). It is an allohexaploid species with complex genome $2 \mathrm{n}=6 \mathrm{x}=42$, AABBDD) is a globally important food crop and will tend to become even more significant with the increase in world population. Common bread wheat is known to have evolved from two spontaneous hybridization events (McFadden 
\& Sears, 1944; Feldman, 2001). Wheat is regarded as king of cereals due to its high acreage, productivity and position in trade. It is the staple food crop for $40 \%$ of the world population and occupies 221.11 mha area in world with $749.46 \mathrm{mt}$ production (FAO, 2014). It is most widely grown crop after rice in India with 30 mha acreage, $98.51 \mathrm{mt}$ production and $32 \mathrm{q} / \mathrm{ha}$ productivity (IIWBR, 2017). India is the second largest wheat producing country next to China from several years and its share in total food grain production of country is $36 \%$ (Anonymous, 2014; Sharma et al., 2013). Wheat is a source of about $55 \%$ of carbohydrate and $20 \%$ of the food calories. It contains nearly carbohydrate $78.10 \%$, protein $14.70 \%$, fat $2.10 \%$, minerals $2.10 \%$ with considerable amount of vitamins (thiamine and vitamin-B) and minerals (zinc, iron). It is also a source of trace minerals like selenium and magnesium, the nutrients which are essential to health (Adams et al., 2002; Fraley 2003). Micronutrient deficiency is one of the serious concern in today's era with its related consequence such as micronutrient malnutrition called 'Hidden Hunger' which diminishes health, productivity and well being of over half of the global community with major impact on infants, children and women (Mason and Garcia, 1993).Micronutrient deficiencies afflict more than two billion individuals or one in three people, globally (FAO 2015). As per World Health Organization (WHO) report, iron $(\mathrm{Fe})$, zinc $(\mathrm{Zn})$ and vitamin-A are the three nutrients that are limiting to human body (Ortiz-Monasterio et al., 2007). There is an opportunity for agriculturist in developing nutrient dense staple food crops (Underwood, 2000) which could help in combat with malnutrition (Calderini and Ortiz-Monasterio, 2003). The major micronutrients being focused in this approach for wheat are iron and zinc. Crop improvement for bio-fortification mainly focuses on the available genetic diversity for iron, zinc along with subsequent screening and characterization of agronomic and enduse features. The development of wheat varieties with high iron and zinc content should be objective of many breeding programmes. We need to have the knowledge about genetic variability in this regard as it reveals about the presence of variation and hence provides basis for an effective selection scheme (Rajshree and Singh, 2018). Also, it is universally approved that higher the genetic variability in the starting material, more is the genetic improvement in the progenies. Studies on genetic variability provide a clear picture of trait wise variation in the experimental material. Proper and precise information on the nature and degree of genetic divergence is very important to plant breeder in selecting diverse parents for a purposeful hybridization (Arunachalam, 1981; Samsuddin, 1985). The existing variability could be determined by estimating Genotypic and phenotypic coefficient of variation. Genetic parameters viz., heritability and genetic advance under selection for different characters are very useful for predicting genetic gain under selection and in adopting efficient strategies in breeding programme (Falconer and Mackay, 1996). Higher is the genetic divergence between parents, higher amount of heterosis can be achieved in progeny (Joshi and Dhawan, 1966). Keeping the above facts in mind a study on 15 genotypes were conducted with the main objectives a) estimation of heritability, genetic advance, PCV (phenotypic coefficient of variation) and GCV (genotypic coefficient of variation) and b) determination of the extent of genetic variability for various characters.

\section{Materials and Methods}

In this study, fifteen genotypes were undertaken to analyse the diversity and variability. The present investigation was carried out at the Experimental Farm, Institute of Agricultural sciences, Banaras Hindu 
University, Varanasi $\left(83^{\circ} 03^{\prime} \mathrm{E}\right.$ and $25^{\circ}$ $\left.23.5^{\prime} \mathrm{N}\right)$ during Rabi season 2016-18. Experimental material consisted of fifteen genotypes like BHU3, BHU6, BHU22, BHU24, BHU28, BHU30, BHU31, BHU35, BHU36, BHU37, BHU38, BHU39, BHU40, BHU21 and HD2967. Experiment was conducted in Randomised Block Design with three replications for each genotype. Each genotype was planted in one meter row with two rows per genotype and distance between the rows was $22.5 \mathrm{~cm}$. Plant to plant distance was maintained $5 \mathrm{~cm}$. Field was irrigated timely and all the recommended cultural and agronomic practices were followed. The observations were recorded on three randomly selected plants from each genotype in each replication on following 14 morphological characters viz., Days to Heading (DH), Normalized Difference Vegetation Index (NDVI), Soil Plant Analysis Development (SPAD), Canopy Temperature (CT), Plant Height (PH), Peduncle Length (PL), Spikelet Per Spike (SPS), Spike Length (SL), Plot Yield (PY), Biomass (BM), Thousand Grain Weight (TGW), Iron Content (Fe), Zinc Content $(\mathrm{Zn})$ and Days to Maturity (DM). NDVI (Normalized Difference Vegetation Index) was measured using handheld sensor Green Seeker. Chlorophyll content was measured using SPAD-502 Chlorophyll meter) and Canopy Temperature Depression (CTD) was measured by handheld Infrared Thermometer (Sixth Sense LT-300) equipment. Iron and zinc content was measured using XRF (X- ray fluorescence machine) using X-ray absorption spectroscopy method. These observations were recorded singly for each genotype. The pooled ANOVA was carried out from total over the replicated data of each environment and all these traits were analysed using Panse and Sukhatme (1969) model for ANOVA (analysis of variance). Searle (1961) method was used for estimating Phenotypic and Genotypic coefficient of variation (PCV and
GCV). Broad sense heritability $\left(h^{2}\right)$ and genetic advance as per cent of mean were determined using Allard (1960) formula. Genetic divergence for fifteen genotypes were estimated using Mahalanobis (1936) $\mathrm{D}^{2}$ statistic. The Tocher's method as described by Rao (1952) was used for clustering the $\mathrm{D}^{2}$ values. Statistical analysis of the recorded data was done by INDOSTAT software for the fifteen genotypes.

\section{Results and Discussion}

\section{ANOVA}

The analysis of variance for 14 different traits is presented in Table 1. All traits were found significantly different for treatment except canopy temperature (CT). Highly Significant differences was found for 9 traits viz., Days to Heading (DH), Normalized Difference Vegetation Index (NDVI), Soil Plant Analysis Development (SPAD), iron content (Fe), zinc content (Zn), Thousand Grain Weight (TGW) among 15 genotypes but moderately significant differences were found for 5 traits viz., Spike Length (SL), Plot Yield (PY), Biomass (BM), Days to maturity (DM) among 15 genotypes. Badakhshan et al., 2013 also found significant differences for iron and zinc content. Hence it shows the presence of variability between the different genotypes which provides enough opportunity for selection and improvement of traits. The extent of variability resulted either from different genetic material or from the effect of environment.

\section{PCV and GCV}

Genetic variability is needed for success of breeding programme. So traits showing wide range of variation in the study have maximum scope for giving positive response in selection scheme. An insight into the genotypic and phenotypic component of variability proves to 
be useful while studying about variability in a population.

Coefficient of variation for all the 14 traits under study is shown in table 2. Phenotypic and genotypic coefficient of variation was expressed as percentage and mentioned in the table 2.

PCV values for all traits ranged from $1.77 \%$ (Canopy temperature) to $13.04 \%$ (peduncle length). PCV and GCV values for thousand grain weight are 6.785 and 6.643 respectively. Reports of Singh et al., (1996) and Sharma et al., (1998) support our results for 1000 grain weight for GCV and PCV respectively. The value of $\mathrm{GCV}$ ranges from $1.63 \%$ (CT) to $11.15 \%$ (PL). The values of PCV and GCV were low for all the traits which indicated that environment has no effect on characters under study. Our findings were supported by Pawar et al., (1989) who reported low PCV and GCV for number of spikelets per spike and spike length. Whereas, Dixit and Patil (1983) reported high PCV and Sharma et al., (1998) reported low PCV and GCV for peduncle length. Lowest value of PCV and GCV was reflected for canopy temperature. These reports were supported by findings of Singh $e t$ al., (2001) and Cheema et al., (2006). Arpitha et al., (2017) found similar results with moderate levels of PCV and GCV for the traits like number of tillers per meter length, number of spikelets per spike and thousand grain weight. Arya et al., (2017) found that least difference between PCV and GCV was noticed for number of spikelets per spike.

\section{Heritability and genetic advance}

The coefficient of variation indicated only the extent of variability present in these characters and does not indicate the heritable portion. This could be ascertained from heritability estimates which in broad sense include both additive and non-additive gene effects and in narrow sense include the proportion of heritable variation which is due to additive component (Lush, 1949). The knowledge of heritability is helpful in assessing merits and demerits of a particular trait as it enables the plant breeder to decide the course of selection procedures to be followed under a given situation.

The estimates of heritability (broad sense) and genetic advance expressed as percent and presented in the Table 2. The table revealed that the estimates of heritability (broad sense) showed a very high range among different traits under study. Highest heritability was observed for thousand kernel weight (95.84 $\%$ ) followed by days to heading (90 \%). Kuchel et al., (2007) also reported thousand kernel weight as an important trait due to its phenotypic stability and high heritability. Yadav et al., (2014) also observed similar results with high heritability for days to $50 \%$ flowering, days to maturity, grain per spike, test weight and grain yield per plant. Moderate level of heritability was found for traits like zinc content, biomass, plot yield followed by NDVI. These results are in accordance with the results of Gupta and Verma (2000), Laghari et al., (2010) and Khan and Ali (2003).

Heritability estimate is more reliable when coupled with genetic advance values and aids in effective selection. Moderate estimates of genetic advance as per cent mean were calculated for character like peduncle length (19.64), thousand kernel weight (13.40), spike length (12.48), iron content (11.88), plot yield (10.69). However, lower genetic advance was found in case of spikelet per spike (9.08), zinc content (8.20) and days to heading (7.53), plant height (7.15), biomass (5.56) followed by Soil Plant Analysis Development (SPAD) which had value of 4.59 and NDVI (4.51) days to maturity (4.34). Canopy temperature had lowest genetic advance value as per cent 
mean (3.09). High heritability with low genetic advance as per cent mean was evident for traits such as DH, SPAD, NDVI, CT, PH, SPS, DM and zinc content. Plot yield show moderate heritability with low genetic advance. These findings were in agreement with studies of Kumar and Lutra (1995) who reported low genetic advance for number of days to 50 per cent flowering and number of grains per spike. Nirmala and Jha (1998) also reported low genetic advance for number of grains per spike. Baranwal et al., (2012) also found similar results for high heritability with low genetic advance in per cent of mean for days to heading which indicated the involvement of non-additive gene action for the expression of this character and selection for such trait might not be rewarding.

\section{Diversity analysis}

\section{Grouping of genotypes into clusters}

Genetic diversity plays an important role in plant breeding because hybrid between lines of diverse origin display a greater heterosis than those between closely related parents. Diversity analysis was done following the Mahalanobis's $\mathrm{D}^{2}$ statistic as described by Rao (1952). $D^{2}$ statistics measures the forces of differentiation at intra and inter cluster levels and determines the maximum divergence displayed by clusters which are separated by the largest statistical distance.

All the 15 genotypes were grouped into six clusters on the basis of $\mathrm{D}^{2}$ values using Tocher's method (Rao, 1952) and the distribution of genotypes into six clusters in shown in Table 3 and shown presented in fig. 1. Out of six clusters, cluster I was the largest comprises 7 genotypes viz., BHU 24, BHU 37, BHU 40, BHU 31, BHU 21, BHU 28, BHU 39 while the second largest cluster was Cluster II with four genotypes viz., BHU 22, BHU 30, BHU 38, BHU 3. Cluster III, cluster IV, V and VI possesses only single genotype each namely BHU 35, BHU 6, HD 2967 , BHU 36 respectively. The grouping of genotypes into different cluster by using Tocher's method was also reported by Tsegaye et al., (2014), Khodadadi et al., (2011) and Singh et al., (2013).

\section{Average Cluster mean for 14 different morphological traits}

Average Cluster mean for different morphological traits in 15 wheat genotypes were presented in Table 4 . The cluster mean values for different characters indicated considerable difference between the clusters for the characters studied. Maximum value for most of the traits was found in Cluster III while least value of most of the traits was found in cluster $\mathrm{V}$.

For days to heading, the cluster VI exhibited the lowest cluster mean value (69.83) and cluster $\mathrm{V}$ exhibited highest mean values (76.5). While for the NDVI the cluster VI observed the least cluster mean value $(0.51)$ and cluster II exhibited the highest cluster mean value (0.56). For the SPAD, cluster II showed least cluster mean value (47.9) while in cluster III observed mean cluster value was highest (51.67). Value of Canopy Temperature was least for cluster IV and V with 21.4 and maximum of 21.99 for cluster II. These values showed only little difference. For the days to maturity, cluster IV showed the least cluster mean (110.17) and cluster III showed the highest mean cluster value (117.50).In case of plant height, cluster $\mathrm{V}$ as a least mean cluster value (82.33) while the cluster IV exhibited the highest cluster mean value (96.31). For the peduncle length, cluster $\mathrm{V}$ observed the least mean cluster value of (17.36) while the cluster III observed the highest mean cluster value of (22.61). For the number of Spikelet per spikes cluster I and II exhibited the least cluster mean value (18.08) and cluster VI exhibited the highest mean cluster value (20). 
Table.1 Analysis of variance of all the 14 traits among 15 genotypes of wheat

\begin{tabular}{|c|c|c|c|c|c|c|c|c|c|c|c|c|c|c|c|}
\hline $\begin{array}{l}\text { Source of } \\
\text { Variation }\end{array}$ & Df & DH & NDVI & SPAD & CT & PH & PL & SPS & SL & PY & BM & TGW & $\mathbf{F e}$ & $\mathbf{Z n}$ & DM \\
\hline Year & 1 & $567.511 * * *$ & $4.108 * * *$ & $74.401 * * *$ & 0.013 & 169.415 & $83.116^{* * *}$ & 3.106 & $52.884 * * *$ & $96851.8^{* * * *}$ & 48673.9 & $162.355^{* * * *}$ & $432.964 * * *$ & $110.224 * *$ & 38.677 \\
\hline Rep & 2 & 0.311 & $0.013 * * *$ & 6.021 & 1.242 & 6.980 & 11.899 & 0.801 & 3.098 & 4200.56 & 16724.9 & 147.471 & 28.241 & 17.476 & 9.411 \\
\hline Entry & 14 & $53.187 * * *$ & $0.005 * * *$ & $17.751 * * *$ & 0.883 & $121.235^{* * *}$ & $39.639 * * *$ & $7.127 * * *$ & $5.746^{* *}$ & $5985.65 * *$ & $35076.3 * *$ & $60.510 * * *$ & $58.496 * * *$ & $35.368 * * *$ & $43.044 * *$ \\
\hline $\begin{array}{l}\text { Year*Entr } \\
\mathbf{y}\end{array}$ & 14 & $5.320 * *$ & 0.003 & 6.384 & 0.133 & 37.491 & $10.644 * *$ & 1.848 & 1.673 & 2695.6 & 23982.8 & 2.514 & $18.202 * * *$ & 16.641 & 4.558 \\
\hline Error & 58 & 2.414 & 0.00078 & 4.052 & 0.667 & 25.597 & 3.127 & 1.126 & 2.421 & 2101.11 & 17433.4 & 8.747 & 4.499 & 6.568 & 11.227 \\
\hline $\mathrm{CV}$ & & 2.11 & 5.17 & 4.07 & 3.76 & 5.659 & 8.969 & 5.79 & 13.587 & 13.697 & 14.74 & 6.31 & 5.68 & 7.39 & 2.94 \\
\hline LSD & & 1.80 & 0.03 & 2.33 & 0.94 & 5.85 & 2.04 & 1.23 & 1.80 & 52.97 & 152.59 & 3.42 & 2.45 & 2.96 & 3.87 \\
\hline
\end{tabular}

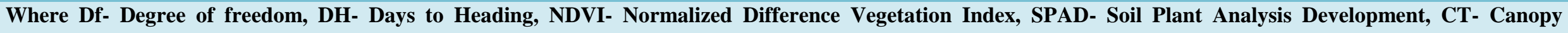

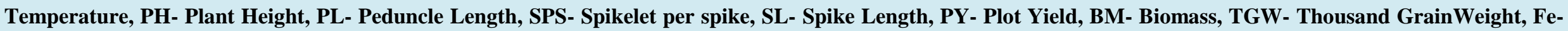
Iron content, Zn- Zinc content, DM- Days to Maturity, CV-Coefficient of Variation, LSD- Least Significant Difference

**.P value at $5 \%$ level of significance, $* * *$. $P$ value at $1 \%$ level of significance 
Table.2 Mean, Minimum and Maximum for all the 19 traits under study

\begin{tabular}{|l|l|l|l|l|l|l|l|l|}
\hline Traits & Mean & Min & Max & $\begin{array}{l}\text { CV } \\
(\boldsymbol{\%})\end{array}$ & PCV & GCV & H & $\begin{array}{l}\text { GA as } \\
\text { mean }\end{array}$ \\
\hline DH & 73.31 & 69.33 & 79.83 & 2.11 & 4.061 & 3.853 & 89.996 & 7.529 \\
\hline NDVI & 0.54 & 0.50 & 0.61 & 5.17 & 5.388 & 3.435 & 40.654 & 4.512 \\
\hline SPAD & 49.39 & 44.84 & 51.67 & 4.07 & 3.482 & 2.787 & 64.037 & 4.594 \\
\hline CT & 21.72 & 21.21 & 22.83 & 3.76 & 1.767 & 1.628 & 84.870 & 3.089 \\
\hline PH & 89.41 & 81.03 & 96.31 & 5.66 & 5.028 & 4.179 & 69.075 & 7.154 \\
\hline PL & 19.72 & 14.92 & 23.22 & 8.97 & 13.036 & 11.149 & 73.147 & 19.643 \\
\hline SPS & 18.32 & 16.56 & 20.00 & 5.79 & 5.950 & 5.120 & 74.061 & 9.078 \\
\hline SL & 11.45 & 9.31 & 13.22 & 13.59 & 8.546 & 7.195 & 70.874 & 12.478 \\
\hline PY & 334.67 & 279.58 & 412.75 & 13.70 & 9.438 & 6.997 & 54.966 & 10.686 \\
\hline BM & 895.57 & 761.67 & 1028.83 & 14.74 & 8.538 & 4.801 & 31.627 & 5.562 \\
\hline TGW & 46.80 & 37.99 & 50.54 & 6.31 & 6.785 & 6.643 & 95.844 & 13.397 \\
\hline Fe & 37.31 & 33.47 & 44.58 & 5.68 & 8.370 & 6.946 & 68.883 & 11.876 \\
\hline Zn & 32.31 & 28.57 & 36.92 & 7.39 & 7.514 & 5.467 & 52.947 & 8.195 \\
\hline DM & 113.74 & 109.50 & 117.50 & 2.94 & 2.355 & 2.227 & 89.409 & 4.337 \\
\hline $\begin{array}{l}\text { Where DH- Days } \\
\text { Temperature, PH- Plant Height, PL- Peduncle Length, SPS- Spikelet per spike, SL- Spike } \\
\text { Length, PY- Plot Yield, BM- Biomass, TGW- Thousand GrainWeight, Fe- Iron content, } \\
\text { Zn- Zinc content, DM- Days to Maturity }\end{array}$ & Heading, SPAD- Soil Plant Analysis Development, CT- Canopy \\
\hline
\end{tabular}

Table.3 Clusters with the Genotypes

\begin{tabular}{|l|l|}
\hline Cluster 1 & BHU 24, BHU 37, BHU 40, BHU 31, BHU 28, BHU 39 \\
\hline Cluster 2 & BHU 22, BHU 30, BHU 38, BHU 3 \\
\hline Cluster 3 & BHU 35 \\
\hline Cluster 4 & BHU 6 \\
\hline Cluster 5 & HD 2967 \\
\hline Cluster 6 & BHU 36 \\
\hline
\end{tabular}


Table.4 Mean of 15 different traits under study in six clusters

\begin{tabular}{|l|l|l|l|l|l|l|l|l|l|l|l|l|l|l|}
\hline & DH & NDVI & SPAD & CT & PH & PL & SPS & SL & PY & BM & TGW & Fe & Zn & DM \\
\hline Cluster 1 & 73.57 & 0.54 & 49.6 & 21.66 & 90.31 & 19.41 & 18.08 & 11.11 & 336.61 & 907.88 & 47.65 & 37.41 & 31.79 & 114.09 \\
\hline Cluster 2 & 73.12 & 0.56 & 47.9 & 21.99 & 86.92 & 19.36 & 18.08 & 11.56 & 319.58 & 825.46 & 44.61 & 35.8 & 33.56 & 112.63 \\
\hline Cluster 3 & 73.83 & 0.55 & 50.37 & 21.88 & 86.78 & 22.61 & 18.22 & 12.36 & 373.17 & 987.67 & 47.75 & 37.05 & 32.2 & 117.5 \\
\hline Cluster 4 & 72 & 0.53 & 51.67 & 21.4 & 96.31 & 22.5 & 18.78 & 11.53 & 319.98 & 998.33 & 49.3 & 44.58 & 34.85 & 110.17 \\
\hline Cluster 5 & 76.5 & 0.51 & 49.6 & 21.4 & 82.33 & 17.36 & 18.89 & 10.67 & 412.75 & 1028.83 & 42.42 & 36.1 & 28.57 & 115.33 \\
\hline Cluster 6 & 69.83 & 0.51 & 50.49 & 21.5 & 95.86 & 19.97 & 20 & 13.22 & 279.58 & 761.67 & 50.54 & 36.82 & 32.32 & 114 \\
\hline
\end{tabular}

Where DH- Days to Heading, NDVI- Normalized Difference Vegetation Index, SPAD- Soil Plant Analysis Development, CTCanopy Temperature, PH- Plant Height, PL- Peduncle Length, SPS- Spikelet per spike, SL- Spike Length, PY- Plot Yield, BM- Biomass, TGW- Thousand GrainWeight, Fe- Iron content, Zn- Zinc content, DM- Days to Maturity

Table.5 Cluster Distances of Different Clusters

\begin{tabular}{|l|l|l|l|l|l|l|}
\hline & Cluster 1 & Cluster 2 & Cluster 3 & Cluster 4 & Cluster 5 & Cluster 6 \\
\hline Cluster 1 & 2543.08 & 8601.45 & 8831.75 & 9681.44 & 21638.47 & 25783.44 \\
\hline Cluster 2 & & 1055.16 & 29638.64 & 30503.98 & 50515.85 & 6210.58 \\
\hline Cluster 3 & & & & 3161.15 & 3378.55 & 59965.8 \\
\hline Cluster 4 & & & & & 9979.33 & 57740.96 \\
\hline Cluster 5 & & & & & & 89440.28 \\
\hline Cluster 6 & & & & & & \\
\hline
\end{tabular}

Fig.1 Cluster diagram indicating dispersion of genotype under divergent clusters

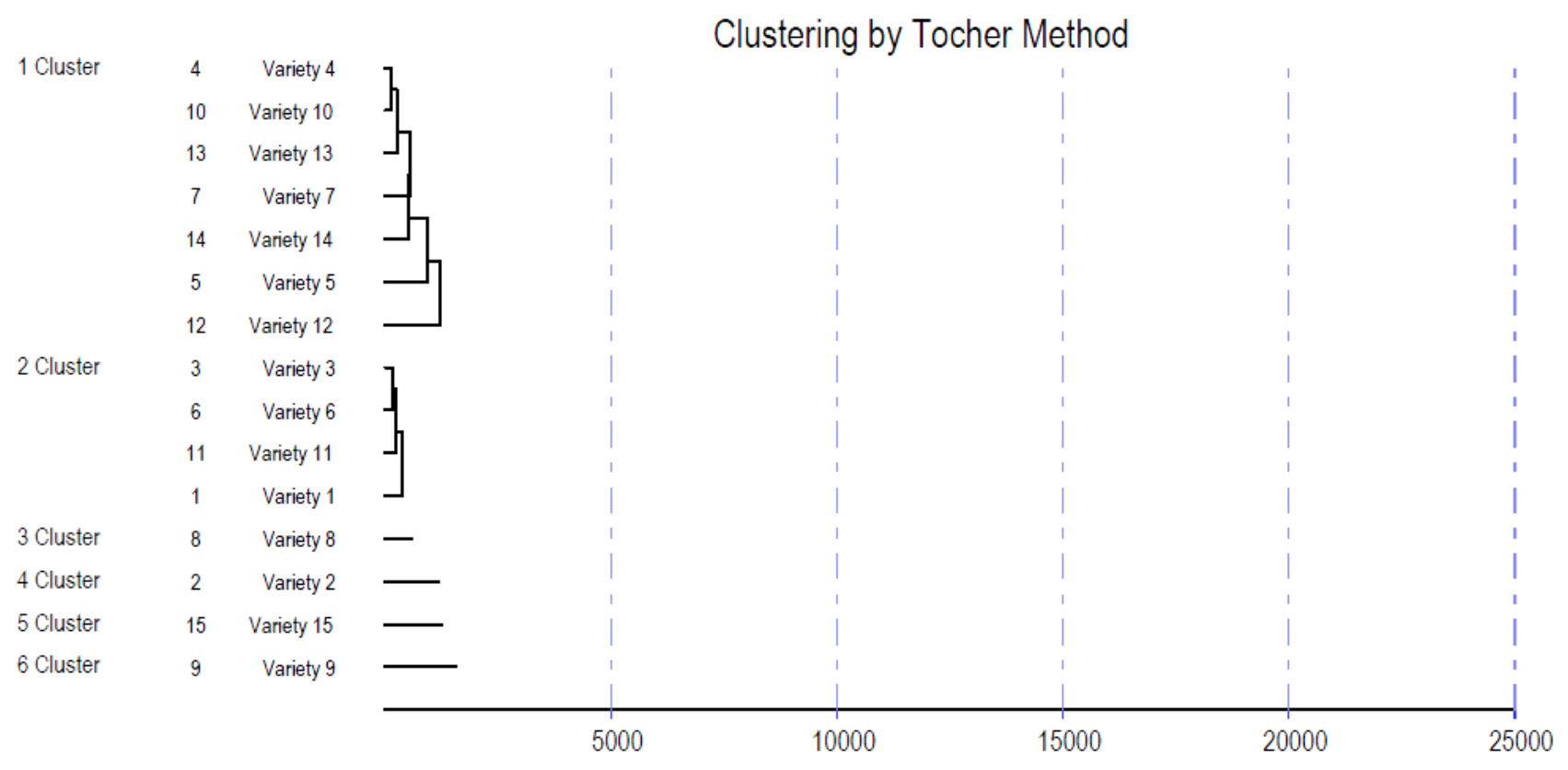


Fig.2 Relative Deposition of Cluster showing average genetics $\left(\mathrm{D}^{2}\right)$ between and within them by Tocher's Method

\section{Tocher Method}

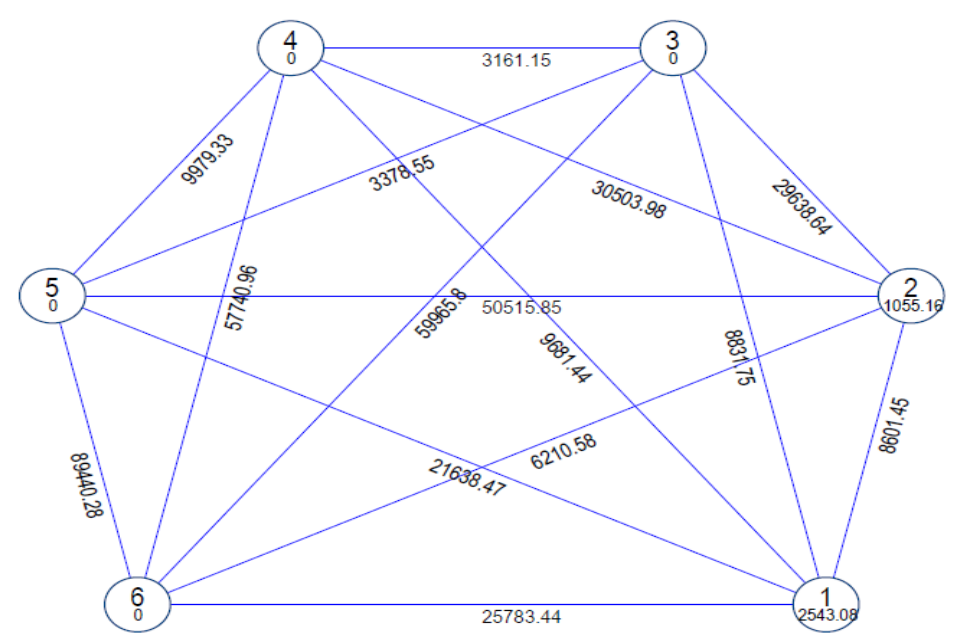

Mahalnobis Euclidean Distance (Not to the Scale)

In the case of Spike length, cluster $\mathrm{V}$ showed the least mean cluster value (10.67) while the cluster III showed the highest mean cluster value (12.36).For the Biomass, there was large difference observed between the clusters. Cluster VI exhibited the least mean cluster value (761.67) and cluster V exhibited the highest mean cluster value of (1028.83) for biomass. In case of plot yield, there is huge cluster difference among in clusters with cluster VI exhibited least mean cluster value (279.58) while cluster $\mathrm{V}$ exhibited the highest cluster mean value of (412.75). For the trait like thousand kernel weight, the cluster $\mathrm{V}$ exhibited the least cluster mean value (42.42) and the cluster VI exhibited the highest cluster mean value of (50.54). Traits like Iron and zinc content showed maximum value for cluster IV with 44.58 and 34.85 respectively but minimum value for iron content was found in cluster II with 35.8 and for zinc content in cluster V with 28.57. Days to maturity was found least in cluster IV with 110.17 while it was highest in cluster III with 117.5 .

\section{Cluster distances among six clusters}

The cluster distances among six clusters are presented in Table 5 and shown in fig. 2. The cluster distances clearly indicate that the Cluster V and cluster VI have the largest distance (89440.28) followed by cluster VI and cluster III having distance (59965.8) and cluster IV and VI (57740.96) representing a huge level of diversity among these clusters and this kind of diverse groups fulfils the criteria needed for a breeding programme. Cluster II and V had value of 50515.85 indicating moderate to high level of distance between these group for the considered characters. The least value of cluster distance was found between cluster III and IV with value 3161.15. Others clusters which have the lesser distances are between cluster V and III with 3378.55. Distance between cluster III and IV is 33669.43.

Intra-cluster distance was found 2543.08 for cluster I and 1055.16 for cluster II while it was zero for the cluster III, IV, V and VI. 
In conclusion, the study conducted on fifteen different wheat germplasm for assesing morpho-physiological traits revealed that zinc content show moderate heritability with low genetic advance. Clustering classified genotypes into 6 groups and exhibited that genotype in cluster IV has highest mean values for zinc and iron content so use of genotype belonging to this group will be most preferable for breeding targeted for biofortification for these micronutrient. The study also deduces that crosses between the Cluster V \& VI and cluster III \& VI will give maximum number of segregants and thus is good for varietal improvement as there is sufficient amount of divergence present which could further be used for exploitation of heterosis.

Abbreviations: ANOVA: Analysis of Variance; GCV: Genotypic Coefficient of Variation; PCV: Phenotypic Coefficient of Variation

\section{References}

Adams, M. L., Lombi, E., Zhao, F. J., \& McGrath, S. P. (2002). Evidence of low selenium concentrations in UK breadmaking wheat grain. Journal of the Science of Food and Agriculture, 82:1160-1165.

Allard, R. W. (1960). Principles of plant breeding. John Wiley and Sons, Inc. New York.

Anonymous, (2014). Progress Report of all India Coordi-nated Wheat and Barley Improvement Project, 1-5 pp Sharma Indu (Ed). Directorate of Wheat Research, Karnal.

Arpitha, H. R., Naik, R. V., \& Anil Kumar, G. (2017). Study of Genetic Variability Parameters For Yield And Yield Attributing Traits in F5 Population of Dicoccum Wheat. Bulletin of Environment, Pharmacology and Life
Sciences, 6: 189-193.

Arunachalam, V. (1981). Genetic distance in plant breeding. Indian Journal of Genetics and Plant Breeding, 41: 226236.

Arya, V. K., Singh, J., Kumar, L., Kumar, R., Kumar, P., \& Chand, P. (2017). Genetic variability and diversity analysis for yield and its components in wheat (Triticum aestivum L.). Indian Journal of Agricultural Research, 51: 128-134.

Badakhshan, H., Moradi, N., Mohammadzadeh, H., \& Zakeri, M. R. (2013). Genetic variability analysis of grains $\mathrm{Fe}, \mathrm{Zn}$ and beta-carotene concentration of prevalent wheat varieties in Iran. International Journal of Agriculture and Crop Sciences, 6: 57.

Baranwal, D. K., Mishra, V. K., Vishwakarma, M. K., Yadav, P. S., \& Arun, B. (2012). Studies on genetic variability, correlation and path analysis for yield and yield contributing traits in wheat (T. aestivum L. em Thell.). Plant Archives, 12: 99-104.

Calderini, D.F., \& Ortiz-Monasterio, I. (2003) Are synthetic hexaploids a means of increasing grain element concentrations in wheat. Euphytica, 134: 169-178.

Cheema, N. M., Mian, M. A., Ihsan, M., Rabbani, G., \& Mahmood, A. (2006). Studies on variability and some genetic parameters in spring wheat. Pakistan Journal of Agriculture Science, 43: 3235.

Dixit, R. N., \& Patil, V. P. (1983). Variability and heritability studies in wheat. Journal of Maharashtra Agricultural Universities, 8: 170-172.

FAO, IFAD, WFP. (2015). The State of Food Insecurity in the World 2015. FAO, Rome

FAOSTAT. (2014). Food and Agriculture Organisation (FAO) of the United Nations, Rome, Italy.

Falconer, D.S., and Mackay, T.F.C. 1996. 
Introduction to Quantitative Genetics 4th ed. Longman, Essex, UK.

Feldman, M. (2001). Origin of cultivated wheat. In: Bonjean A. P., Angus W. J. eds. The world wheat book: A history of wheat breeding. Paris: Lavoisier Tech \& Doc. 3-56.

Fraley, R. T. (2003). Improving the nutritional quality of plants. In: Vasil IK (ed) Plant biotechnology 2002 and beyond. Kluwer, Dordrecht, pp 61-67.

Gupta, S. K., \& Verma, S. R. (2000). Variability, heritability and genetic advance under normal and rainfed conditions in durum wheat (Triticum durum Desf.). Indian Journal of Agricultural Research, 34: 122-125.

Indian Institute of Wheat and Barley Research (IIWBR) (2017). AICRP-W\&B, Progress Report, Crop Improvement.

Joshi, A.B., and Dhawan, N.L. 1966. Genetic improvement of yield with special reference to self-fertilizing crops. Indian J. Genet. 26A: 101-113.

Khan, A. S., Salim, Ishtiaqand., Ali., Zulfikar. (2003). Heritability of various morphological traits in wheat. International Journal of Agricultural Biology, 5, 138-140.

Khodadadi, M., Dehghani, H., Fotokian, M. H., \& Rains, B. (2014). Genetic diversity and heritability of chlorophyll content and photosynthetic indexes among some Iranian wheat genotypes. Journal of Biodiversity and Environmental Sciences, 4: 12-23.

Kuchel, H., Williams, K. J., Langridge, P., Eagles, H. A., \& Jefferies, S. P. (2007). Genetic dissection of grain yield in bread wheat. I. QTL analysis. Theoretical and Applied Genetics, 115: 1029-1041.

Kumar, J., \& Luthra, O. P. (1995). Genetic variability for some quantitative characters in wheat. Haryana Agricultural University Journal of
Research, 25: 1-4.

Laghari, K. A., Sial, M. A., Arain, M. A., Mirbahar, A. A., Pirzada, A. J., Dahot, M. U., \& Mangrio, S. M. (2010). Heritability studies of yield and yield associated traits in bread wheat. Pakistan Journal of Botony, 42: 111115.

Lev-Yadun, S., Gopher, A., \& Abbo, S. (2000). The cradle of agriculture Science, 288: 1602-1603.

Lush, J. L. (1949). Heritability of quantitative characters in farm animals. Hereditas, 35: 356-375.

Mahalanobis, P.C. (1936). On the generalised distance in statistics. Proceedings of National Institute of Science, India, 2: 49-55.

Mason, J. B., \& Garcia, M. (1993). Micronutrient deficiency-the global situation. Scn News, 9, 11-16.

McFadden ES., \& Sears ER. (1944). The artificial synthesis of Triticum spelta. Records of the Genetics Society of America, 13: 26-27.

Nirmala, R. B. P., \& Jha, P. B. (1998). Variability for disease reaction to leaf blight and other traits in inter-varietal crosses of common bread wheat. Journal of Applied Biology, 8.

Ortiz-Monasterio, J. I., Palacios-Rojas, N., Meng, E., Pixley, K., Trethowan, R., \& Pena, R. J. (2007). Enhancing the mineral and vitamin content of wheat and maize through plant breeding. Journal of Cereal Science, 46(3), 293-307.

Panse, V. G., \& Sukhatme, P. V. (1967). Statistical Methods Agricultural Workers, published by Indian Council of Agricultural Research. New Delhi (India).

Pawar, S. V., \& Patil, R. B. (1989). Variability and inheritance of yield components in crosses of wheat. Journal Maharashtra 
Agricultural University, 14:25-37.

Rajshree \& Singh, S. K. (2018). Assessment of Genetic Diversity in Promising Bread Wheat (Triticum aestivum L.) Genotypes. International Journal of Current and Microbiology and Applied Science, 7: 676-684.

Rao, C. R., (1952). Advanced Statistical Methods in Biometrical Research. John Wiley and Sons, New York.

Samsuddin, A. K. M. (1985). Genetic diversity in relation to heterosis and combining analysis in spring wheat. Theoretical and Applied Genetics 70: 306-308.

Searle, S.R., 1961. Phenotypic, Genotypic and environmental correlations. Biometrics 47: 474-480.

Sharma, I., Singh, G., Tyagi, B.S., \& Sharma, P. K. (2013). Wheat Improvement in India: Achievements \& Future Challenges. Souvenir 52 $2^{\text {nd }}$ All India Wheat and Barley Research Workers Meet, Kanpur, India, pp 1-54.

Sharma, P. K., Gupta, P. K., \& Balyan, H. S. (1998). Genetic diversity in a large collection of wheats (Triticum spp.). Indian Journal of Genetics and Plant Breeding, 58: 271-278.

Singh, M. K., Sharma, P. K., Tyagi, B. S., \& Singh, G. (2013). Genetic analysis for morphological traits and protein content in bread wheat (Triticum aestivum L.) under normal and heat stress environments. Indian Journal of Genetics and Plant Breeding, 73(3), 320-324.

Singh, N. K., Tiwari, L. P., \& Joshi, A. K. (1996). Genetic variability and characters association in common wheat. Madras Agricultural Journal, 83: 589-590.

Singh, R. P., \& Rai, A. K. (1987). Genetics of quantitative traits in bread wheat, Madras Agricultural Journal, 74: 1114.

Singh, S. P., Jha, P. B., \& Singh, D. N. (2001). Genetic variability for polygenic traits in late sown wheat genotypes. Annals of Agricultural Research, 22(1): 34-36.

Tsegaye, D., Dessalegn, T., Dessalegn, Y., \& Share, G. (2012). Genetic variability, correlation and path analysis in durum wheat germplasm (Triticum durum Desf). Agricultural Research and Reviews, 1: 107-112.

Underwood, B. A. (2000). Overcoming micronutrient deficiencies in developing countries: Is there a role for agriculture? Food Nutrition Bulletin, 21: 356-360.

Yadav, S.K., Singh, A.K., Baghel, S.S., Jarman, M. and Singh, A.K. 2014. Assessment of genetic variability and diversity for yield and its contributing traits among CIMMYT based wheat germplasm. J. of Wheat Res. 6(2): 154159.

\section{How to cite this article:}

Stuti Krishna, Priyanka Upadhayay, Vinod Kumar Mishra, Shubhra N. Kujur, Monu Kumar and Punam S. Yadav. 2020. Genetic Analysis and Diversity Study among High Zinc Wheat (Triticum aestivum L.) Germplasm. Int.J.Curr.Microbiol.App.Sci. 9(03): 942-953. doi: https://doi.org/10.20546/ijcmas.2020.903.111 